Sonic Scope: New Approaches to Audiovisual Culture

\title{
Monty Williams - An Audio Postcard's Journey
}

\section{Monty Williams}

Published on: Feb 15, 2021

DOI: $10.21428 / 66 f 840 a 4.6 \mathrm{db} 9 \mathrm{~b} 6 \mathrm{f} 6$

License: Creative Commons Attribution 4.0 International License (CC-BY 4.0). 


\section{An Audio Postcard's Journey}

Monty Williams, University of Sheffield

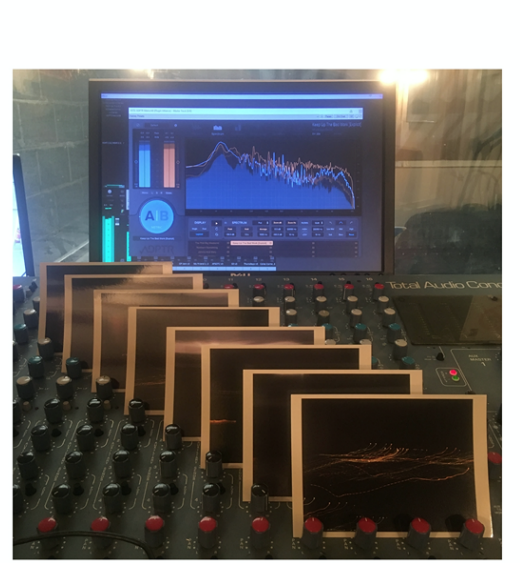

Mixing in Sheffield
An Audio Postcard's Journey

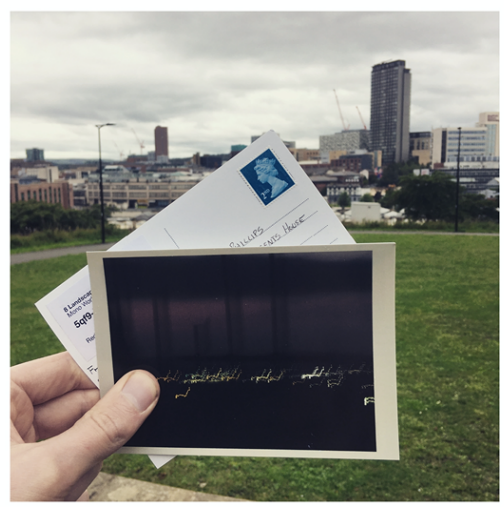

Posted from Sheffield

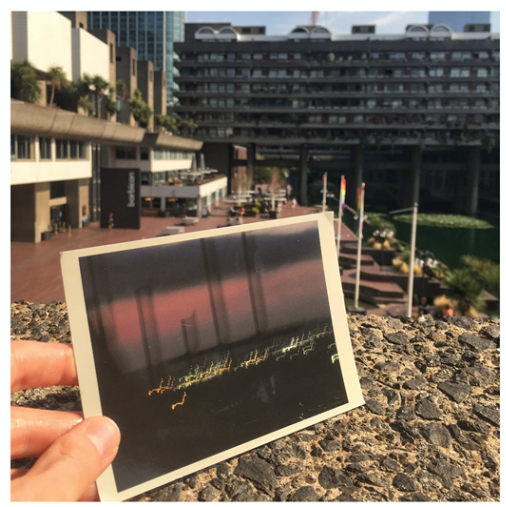

Received in London

An Audio Postcard's Journey, Monty Williams.

I currently practise as a musician and audio-visual artist in Sheffield, where I completed my undergraduate degree in architecture in 2017. Since then I have become increasingly interested in the relationship between music and place. My original recordings are released under the name Mono Works, a reference to solo works in music and Sheffield's industrial heritage with its many "Works" buildings.

Last August I released a set of recordings, titled " 8 Landscapes," through the format of an audio postcard. Eight postcard designs were conceived, using night time landscape photography I'd taken from the window of my studio. They were then released through Bandcamp, with each postcard including a unique download code for the recipient. As the sender, I enjoyed bringing a tacit quality to the world of digitally released music. The images chosen to accompany the music describe the type of atmospheres that have influenced my music creation in Sheffield. I hope that the recipients enjoy the compositions individually, while perhaps viewing their own surrounding landscapes in a new light.

The trio of images I've selected follow an audio postcard's journey, in this case from Sheffield to London. I asked recipients to take an image of the postcard in their own surroundings, which was an 
exciting way to connect with my audience. This link seemed especially important at a time where live performance was not possible due to the year's Covid-19 restrictions.

Further information about the postcards can be found at monoworks.bandcamp.com 